\title{
New Approaches to Total Synthesis of Manzamine A, Ircinal A and Related Compounds
}

\author{
Masako Nakagawa, ${ }^{*}$ Yasuhiro Torisawa, Hideharu Uchida, and Atsushi Nishida
}

Faculty of Pharmaceutical Sciences, Chiba University,

\begin{abstract}
New approaches to total asymmetric synthesis of ircinal A and manzamine A are described. The synthesis utilizes a highly efficient Diels-Alder reaction of the suitably functionalized dihydropyridinones and siloxydienes as a key step, followed by expedient conversion to manzamine $A$.
\end{abstract}

\section{Introduction}

Manzamines are naturally occurring cytotoxic and antibiotic indole alkaloids of the fascinating heterocyclic compounds. Since the first isolation and structural elucidation of manzamine A 1 from a marine sponge collected off Manzano, Okinawa, isolated by Higa (ref. 1) and subsequent characterization of the congeners (manzamine B - F) coupled with the independent isolation of the same alkaloids as keramamines (ref. 2), there has been widespread interest in the unprecedented structures, the biogenesis, and synthesis of these $\beta$-carboline alkaloids, in addition to their biological activities. Further progress was made thereafter by the isolation of new and biogenetically closely related members, which support an ingenious proposal for their biosynthetic pathway, by Baldwin, Whitehead, and Marazano (ref. 3).
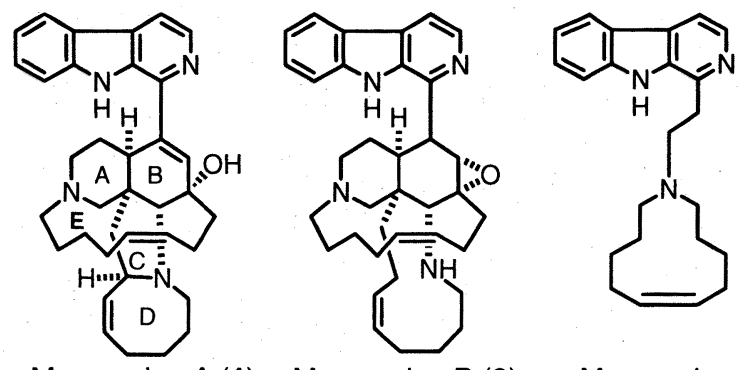

Manzamine A (1)

Manzamine B (2)

Manzamine C (3)

Figure 1. Manazmine A, B and C

While the simplest congener manzamine $\mathrm{C}$ and related compounds have been synthesized in this (ref. 4) and Languor's laboratories (ref. 5), the more complex manzamine A has been a challenging target for total synthesis (ref. 6). Quite recently, Winkler (ref. 7) and Martin (ref. 8) have succeeded in the total synthesis of manzamine $A$ and its related compounds.

We have been interested in developing an efficient route to the tetraazacyclic intcrmediate $\mathbf{4}$ for $\mathbf{1}$ which was based on initial construction of tricyclic intermediate 5: 1) by intermolecular Diels-Alder reaction of functionalized dihydropyridinone as a dienophile with siloxydiene leading to the construction of the cis relationship of the central $\mathrm{AB}$ ring system of this unique structure, followed by intramolecular Michael addition to the tricyclic core 5 (path $a$ ) or 2 ) by an intramolecular fashion (path $b$ ). We also 
focused attention on path $c$ which is suitable for the construction of the $\mathrm{AB}$ ring system, especially for the $\beta$-carboline connection (ref. 9)

\section{Scheme 1}

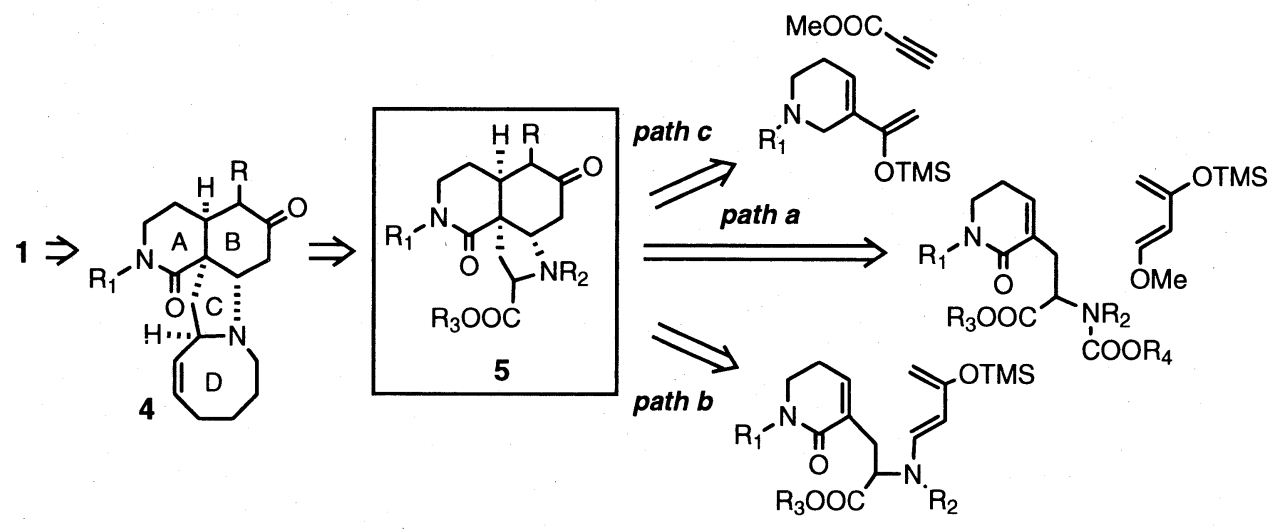

\section{Synthesis of the Tetracyclic Core Structure $( \pm)-20$}

Our initial studies along path a revealed that $N$-alkyl protected (i.e., $\mathrm{R}_{1=a l k y l) ~ d i h y d r o p y r i d i n o n e s}$ were quite sluggish towards dienes even in an intramolecular case, and the electron-withdrawing character of an $N$-protecting group was essential for the successful intermolecular cycloadditions (ref. 10). Further investigation into these thermal transformations led us to select the $N$-benzenesulfonyl dihydropyridinones or $p$-chlorobenzenesulfonyl derivatives as a dienophile in view of the thermal stability of the $N$-arylsulfonyl group. As expected, in the model study using a simple dienophile having an aminoacid residue, it was found that $N$-tosyl-3-alkyldihydropyridinone 6 undergoes Diels-Alder reaction with Danishefsky's diene under conventional thermal conditions affording 7 , which after treatment with an acid followed by a base, was converted to the expected central pyrroloisoquinoline ring system 9 in ca. $40 \%$ yield. We achieved a more facile construction of 9 by utilization of a highpressure Diels-Alder reaction of 6 with the Danishefsky diene in $60 \%$ overall yield for 4 steps (ref. 10).

\section{Scheme 2}

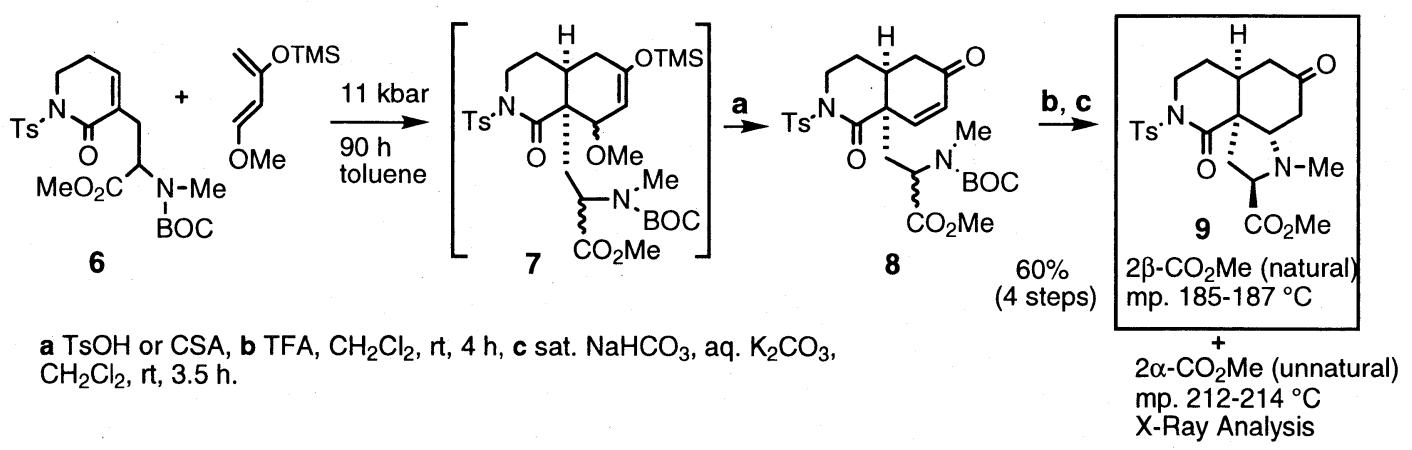

The new dienophiles $\mathbf{1 0}$ and $\mathbf{1 1}$, each having a $\mathrm{COCF}_{3}$ protecting group instead of a thermally unstable BOC group, were found to be suitable due to the ease of preparation (ref. 11) and appropriate reactivity in Diels-Alder reaction under thermal conditions (ref. 12). Thus, treatment of $\mathbf{1 0}$ and $\mathbf{1 1}$, respectively, with Danishefsky's diene in refluxing $p$-cymene afforded the corresponding enones 12 and 13. The SEM enone 12 was deprotected by trifluoroacetic acid (TFA) to furnish the NH-enone, which was readily converted to the tricyclic system 14 by brief treatment with 1,4-diazabicyclo$[2,2,2]$ octane $(\mathrm{DABCO})$ at room temperature. Subsequent ketalization of $\mathbf{1 5}$ afforded the stable ketal $\mathbf{1 6}$ 
as a ca $1: 1$ diastereoisomeric mixture, which could easily be separated by recrystallization from $\mathrm{CH}_{2} \mathrm{Cl}_{2} / \mathrm{Et}_{2} \mathrm{O}$, although the diastereomers corresponding to 15 and $\mathbf{1 6}$ could be separated by column chromatography. For a large scale preparation, these deprotection-cyclization-ketalization steps were conveniently conducted without purification, to furnish the desired isomer 16 in $30 \%$ yield from the $\mathrm{N}$ SEM dienophile 10. Another efficient preparation of 15 was realized by the reaction of $N$-MOM adduct 13 with triethyl triflate (TESOTf) in the presence of $\mathrm{SiO}_{2}$ powder and $\mathrm{Na}_{2} \mathrm{SO}_{4}$.

\section{Scheme 3}

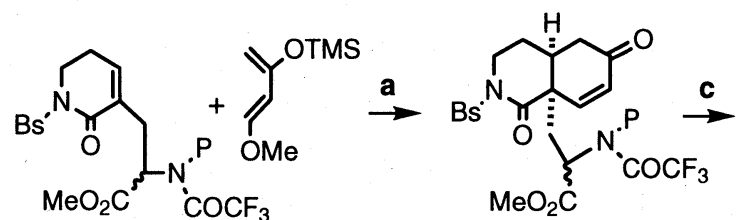

10: $P=S E M$

11: $P=M O M$
$\mathrm{MeO}_{2} \mathrm{C}$$$
\text { 12: } P=S E M, 66 \%
$$

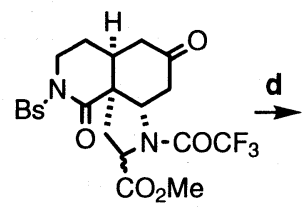

15

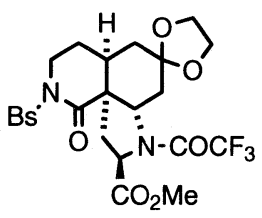

16

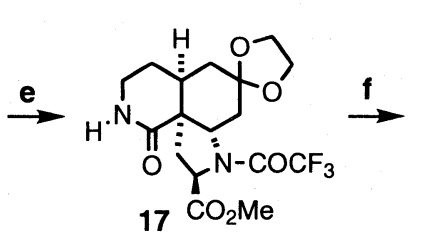<smiles>C[C@H](C=O)N([C@H](C)C=O)[C@H]1CC2(C[C@H]3CCNC(=O)[C@@]32C)OCCO1</smiles>
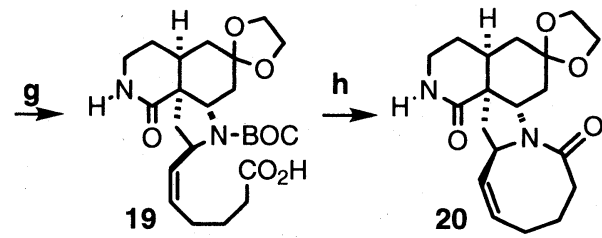

colorless

needle,

$\mathrm{mp}>300^{\circ} \mathrm{C}$

a 1) p-cymene, $\left.180{ }^{\circ} \mathrm{C}, 5 \mathrm{~h}, 2\right) \mathrm{CSA}, \mathrm{CH}_{2} \mathrm{Cl}_{2}, \mathrm{rt}$, b TFA, $\mathrm{CH}_{2} \mathrm{Cl}_{2}, \mathrm{rt}, \mathbf{c} \mathrm{TESOTf}, \mathrm{Na}_{2} \mathrm{SO}_{4}$, toluene, $\mathrm{SiO}_{2}$, rt $(65 \%$, $\mathrm{P}=\mathrm{MOM}$ ), d 1) ethylene glycol, PPTS, benzene, reflux, 2) separation of diastereomers, e $\mathrm{Na}$, anthracene, $\mathrm{DME},-60^{\circ} \mathrm{C}$ $(92 \%)$, f 1) $\left.\mathrm{LiBH}_{4}, \mathrm{~B}(\mathrm{OMe})_{3}, 2\right)(\mathrm{Boc})_{2} \mathrm{O}, \mathrm{NaOH}\left(87 \%, 2\right.$ steps), 3) PCC, $\mathrm{NaOAc}, \mathrm{CH}_{2} \mathrm{Cl}_{2}(67 \%), \mathbf{g}$ $\mathrm{Ph}_{3} \mathrm{P}=\mathrm{CH}\left(\mathrm{CH}_{2}\right)_{3} \mathrm{COOK}$, toluene, it, h 1) TFA, 2) DPPA, Et ${ }_{3} \mathrm{~N}, \mathrm{DMF}, 2$ weeks at $5{ }^{\circ} \mathrm{C}$, then 1 day at it (14\% from 18).

The benzenesulfonyl group used for nitrogen protection and for activation of dihydropyridinone as an efficient dienophile for successive cycloaddition now had to be removed after the Diels-Alder reaction to prevent ring-opening due to the instability of benzenesulfonyl lactam toward nucleophiles.

Subsequent selective deprotection of the two $\mathrm{N}$-protecting groups (i.e., $\mathrm{PhSO}_{2}$ and $\mathrm{CF}_{3} \mathrm{CO}$ ) was best carried out by using $\mathrm{Na} /$ anthracene in 1,2-dimethoxyethane (DME) at $-60{ }^{\circ} \mathrm{C}$, giving 17 . Then, the reductive removal of the $\mathrm{CF}_{3} \mathrm{CO}$ group by $\mathrm{LiBH}_{4} / \mathrm{B}(\mathrm{OMe})_{3}$ followed by protection of the newly generated $\mathrm{NH}$ group by the BOC group gave the aldehyde $\mathbf{1 8}$ (87\%, 3 steps yield). Expedient conversion of $\mathbf{1 8}$ to the precursor 19 was followed by the azocine lactam ring closure to give the desired tetracyclic core structure $\mathbf{2 0}$ in a racemic form (ref. 12).

\section{Synthesis of Optically Active Dienophiles}

From the results obtained, some dihydropyridinones have emerged as potential precursors for the construction of a highly functionalized perhydroisoquinoline ring system in our synthetic approaches to the manzamine alkaloids. We envisioned that developing a general and efficient synthesis for dihydropyridinone derivatives bearing a chiral side chain, would significantly enhance the utility of our Diels-Alder methodology. Therefore, we next directed our attention to the synthesis of optically active tetracyclic core structure 4 via a more efficient method based on the Diels-Alder reaction of siloxydienes with new dienophiles such as $\mathbf{2 0}$ and $\mathbf{2 1}$ as shown in Scheme 4.

We initially investigated the feasibility of a coupling reaction of vinyl iodide $\mathbf{2 2}$ with a chiral organozinc reagent $\mathbf{2 3}$, in the presence of a Pd catalyst under various conditions to introduce the chiral amino acid unit into the 3 position of the pyridinone ring system.

Among the catalyst systems examined, $\mathrm{PdCl}_{2}(\mathrm{PhCN})_{2}(0.2 \mathrm{eq})$ combined in situ with tri-otolylphosphine $(0.4 \mathrm{eq})$ in DMF provided a suitable catalytic species. Under these conditions, dihydropyridinone $\mathbf{2 5}$ a was produced in the best yield (37\%). However, a similar reaction of 
oxazolidine derivative $\mathbf{2 4}$ failed to give $\mathbf{2 5 b}$. Therefore, we investigated another efficient route to obtain $\mathbf{2 0}$ which involves the aldol reaction of $\mathbf{2 6}$ with Garner aldehyde 27.

\section{Scheme 4}

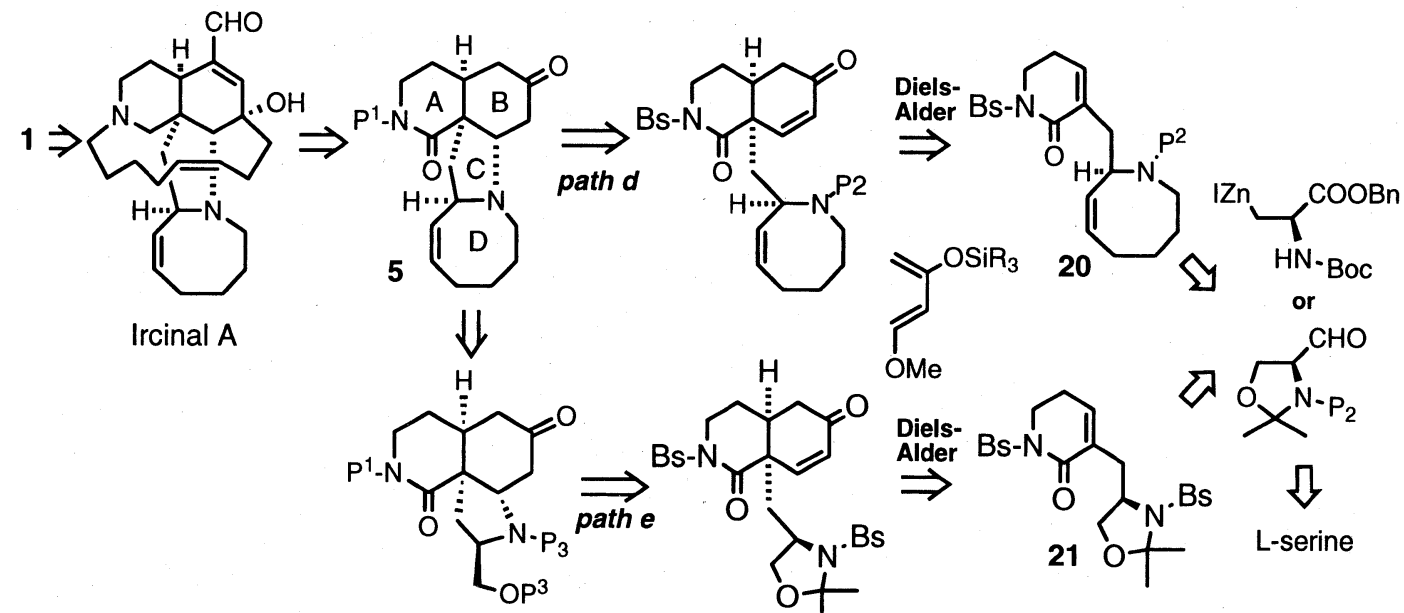

\section{Scheme 5}<smiles>CN1CCC=C(I)C1=O</smiles>

22<smiles>[CH2+]CCC(CC(=O)OCc1ccccc1)NC(=O)OCc1ccccc1</smiles>

23

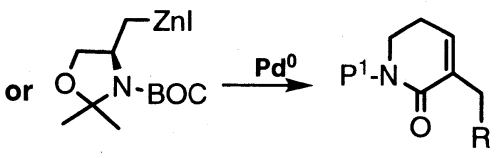

24 25a: $\mathrm{R}={ }^{\mathrm{Y}} \mathrm{NHBO}_{2}^{\mathrm{CH}_{2} \mathrm{Ph}}$

25b: $R=\overbrace{O^{N-B O C}}^{\pi^{n}}$

\section{Scheme 6}

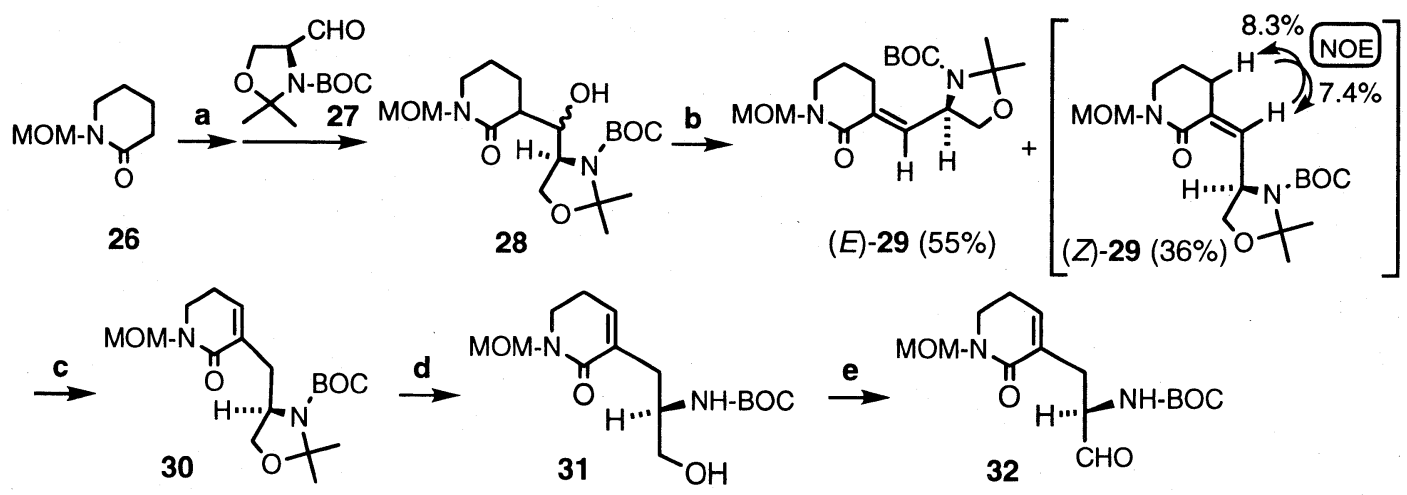

a $\mathrm{LiN}(\mathrm{TMS})_{2}$, THF, $-60^{\circ} \mathrm{C}, 1 \mathrm{~h}$, then $27(91 \%)$, b 1) $\left.\mathrm{Et}_{3} \mathrm{~N}, \mathrm{MsCl},-40 \sim 0{ }^{\circ} \mathrm{C}, 2\right) \mathrm{DBU}$, benzene, rt then $80^{\circ} \mathrm{C}, \mathrm{c}$ $(\mathrm{EtO})_{3} \mathrm{SiH},\left(\mathrm{PPh}_{3}\right)_{3} \mathrm{RhCl}$ (cat.), $\mathrm{Cs}_{2} \mathrm{CO}_{3}$, toluene, reflux (80\% from $\left.(E)-29\right)$, d Amberlyst-15, $\mathrm{MeOH}$, it $(85 \%)$, e Dess-Martin ox., $\mathrm{CH}_{2} \mathrm{Cl}_{2}, 0^{\circ} \mathrm{C}(85 \%)$.

The coupling reaction of 27 with $N$-MOM-piperidone 26 under basic conditions [LiN(TMS) 2 , THF] gave alcohols (28, a mixture of two diastereomers) in a yield of $80-90 \%$, which were then dehydrated to give 29 under usual conditions. After purification, only exo-enones (29, $E$ and $Z$ mixture) were obtained in a $1.5: 1$ ratio (91\% combined yield) which were then subjected to the critical double-bond isomerization to an endo cyclic position as in 30. Extensive experimentation under various conditions, a previously reported protocol $\left[\mathrm{Et}_{3} \mathrm{SiH}, \mathrm{RhCl}\left(\mathrm{Ph}_{3} \mathrm{P}\right)_{3}\right.$, toluene, reflux] (ref. 13) gave more satisfactory 
results, but further optimization was needed. A high-yield isomerization reaction was finally realized when the silane was changed to $(\mathrm{EtO})_{3} \mathrm{SiH}$, and the reaction was conducted in the presence of $\mathrm{Cs}_{2} \mathrm{CO}_{3}$. In this way, the chiral dihydropyridinone derivative $\mathbf{3 0}$ was obtained in $80 \%$ yield from the major isomer $(E)$-29. Deacetonization of $\mathbf{3 0}$ gave aminoalcohol 31, which was then oxidized to the labile aldehyde 32 by Dess-Martin periodinane in excellent yield.
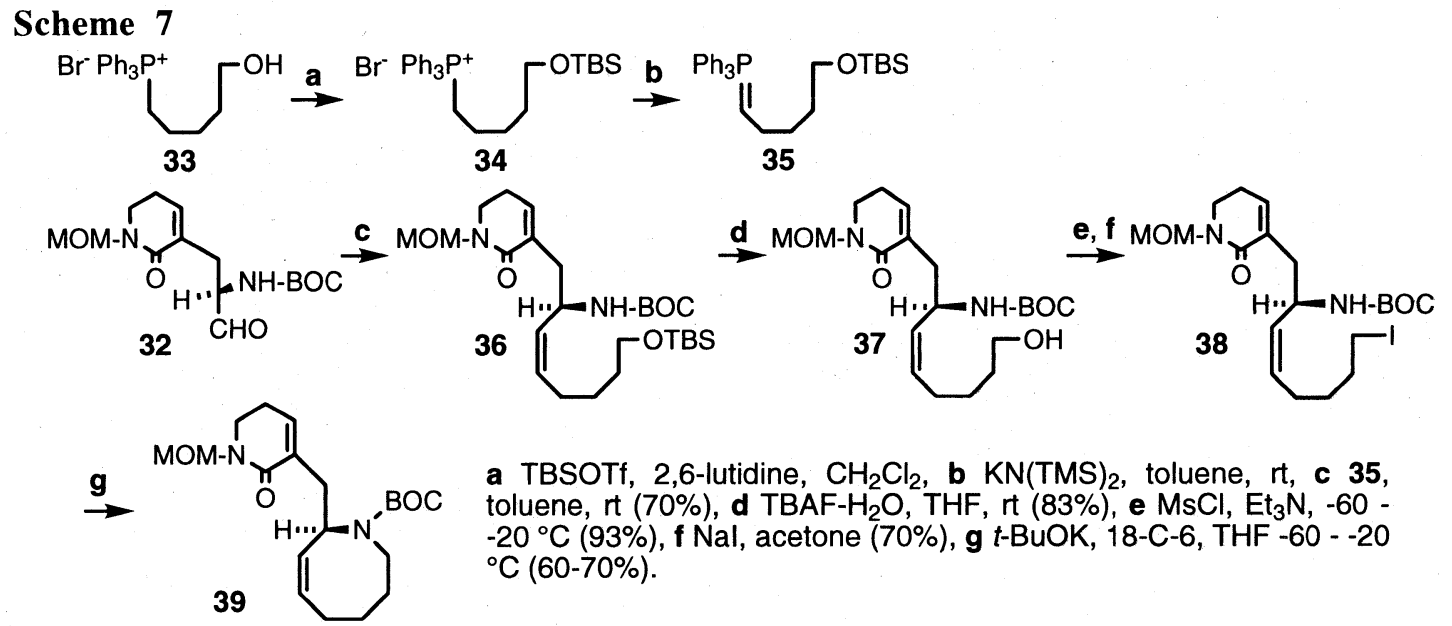

a TBSOTf, 2,6-lutidine, $\mathrm{CH}_{2} \mathrm{Cl}_{2}$, b $\mathrm{KN}(\mathrm{TMS})_{2}$, toluene, $\mathrm{rt}$, c 35, toluene, it $(70 \%)$, d TBAF- $\mathrm{H}_{2} \mathrm{O}$, THF, it $(83 \%)$, e $\mathrm{MsCl}, \mathrm{Et}_{3} \mathrm{~N},-60-$ $-20^{\circ} \mathrm{C}(93 \%)$, f Nal, acetone $(70 \%)$, g $t$-BuOK, 18-C-6, THF $-60--20$ ${ }^{\circ} \mathrm{C}(60-70 \%)$.

For elongation of the C5-carbon chain, Wittig reactions of a conventional Wittig ylide derived from 4-carboxybutyltriphenylphosphonium bromide or 5-hydroxypentyltriphenylphosphonium bromide $\mathbf{3 3}$ (ref. 14) with 32 were carried out, but none of the desired products were obtained with these anionic oxido-ylides. However, Wittig reaction of 32 with the protected ylide 35 gave the desired product 36 in $70 \%$ yield, which was further transformed into 37.

The stage was then set for the crucial azocine ring-forming step. There are two options for the activation of the hydroxyl group towards azocine ring closure. Our previous protocol (ref. 15) suggested the use of a tosylate rather than iodide for such cyclization. However, conversion of $\mathbf{3 7}$ to the $O$-mono tosylate was simply accompanied with $\mathrm{N}, \mathrm{O}$-ditosylation, which did not lead to the desired cyclized product, but rather gave a simple elimination product. Alcohol 37 was then converted to iodide 38 via mesylation followed by treatment with NaI. The iodide $\mathbf{3 8}$ underwent cyclization in the presence of 18 -crown- 6 and $t$-BuOK to give the desired chiral azocine 39 in moderate yield (60-70\%) (ref. 15). However, unexpectedly, the replacement of the MOM group by a benzenesulfonyl group proved unsuccessful. Unfortunately, no satisfactory solution has been found to date. For these reasons, the decision was made to explore the introduction of the double-bond functionality at the 3 position of pyridinone at a later stage of the synthesis. Accordingly, we first reduced the exo double bond with $\mathrm{NiCl}_{2} / \mathrm{NaBH}_{4}$ to $N$-MOM-piperidone $\mathbf{4 0}$. Treatment of $\mathbf{4 0}$ with camphor sulfonic acid (CSA) gave 41.

Oxidation of 41 with pyridine ${ }^{-}$sulfurtrioxide-dimethyl sulfoxide- $\mathrm{Et}_{3} \mathrm{~N}$, followed by Wittig reaction with $\mathrm{Ph}_{3} \mathrm{P}=\mathrm{CH}\left(\mathrm{CH}_{2}\right)_{3} \mathrm{COOK}$, gave compound 43 in $60-70 \%$ yield. The acid was then converted to the alcohol 44 via reduction of the mixed anhydride formed in situ. Similar reaction conditions used for the formation of 39 were applied for the conversion of $\mathbf{4 4}$ to $\mathbf{4 7}$ as illustrated in Scheme 8. Deprotection of 47 was best carried out by treatment with concentrated $\mathrm{HCl}$ in refluxing methanol, which was followed by benzenesulfonylation of the secondary nitrogen to give 48 . Further treatment of 48 with arylsulfonylchloride under strong basic conditions afforded 49 , which was converted to the desired dienophile 50 via phenylselenation followed by oxidative elimination. However, the yields of the last two steps were low. This prompted us to develop an alternative synthesis of chiral dienophiles 51, already carrying a benzenesulfonyl group at an earlier stage that was much easier to prepare on a multimolar scale. 


\section{Scheme 8}

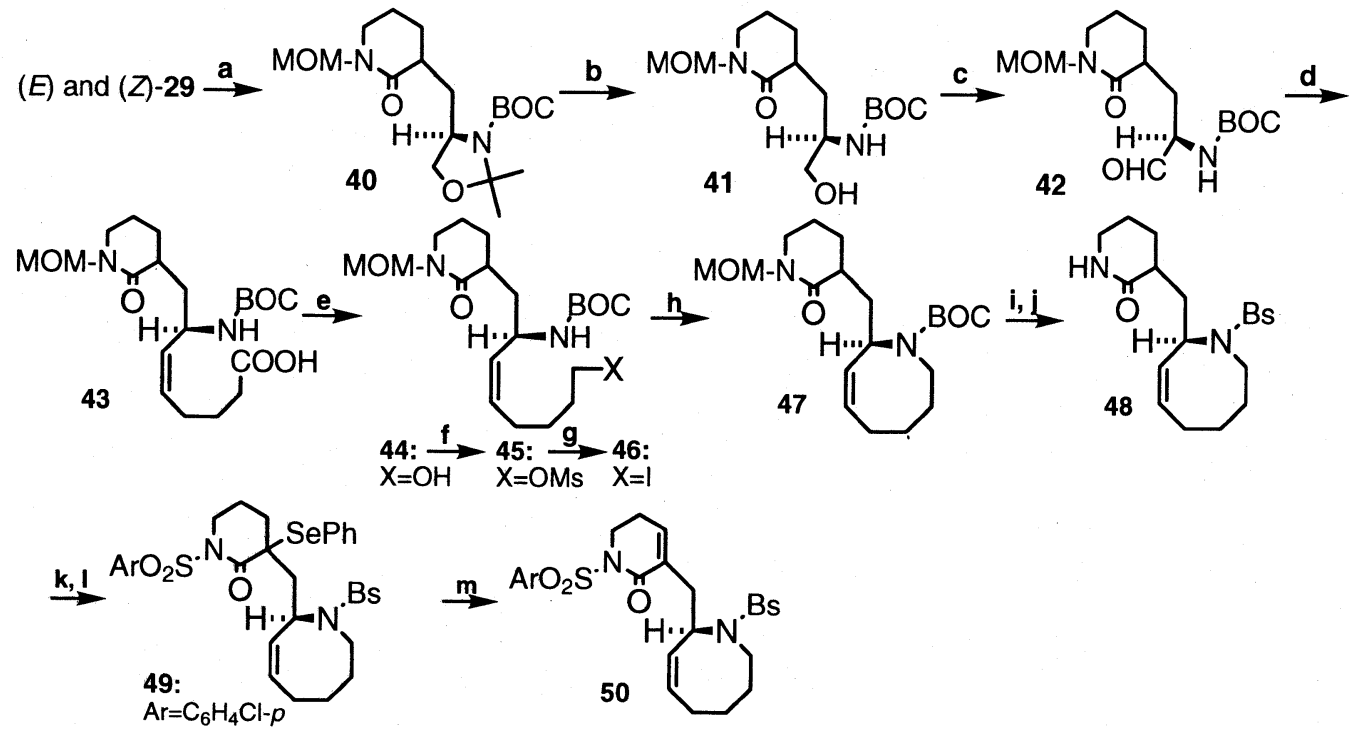

a $\mathrm{NiCl}_{2} \bullet 6 \mathrm{H}_{2} \mathrm{O}$ (cat.), $\mathrm{NaBH}_{4}, \mathrm{MeOH}, 0^{\circ} \mathrm{C}(99 \%)$, b CSA, MeOH, $0{ }^{\circ} \mathrm{C}$ - rt (95\%), c Py•SO 3 , DMSO, $\mathrm{Et}_{3} \mathrm{~N}, \mathrm{CH}_{2} \mathrm{Cl}_{2}$, rt, d $\mathrm{Br}^{\circ} \cdot \mathrm{Ph}_{3} \mathrm{P}^{+}\left(\mathrm{CH}_{2}\right)_{4} \mathrm{COOH}, \mathrm{KN}(\mathrm{TMS})_{2}$, toluene, $0{ }^{\circ} \mathrm{C}\left(60-70 \%, 2\right.$ steps), e ClCOOEt, $\mathrm{Et}_{3} \mathrm{~N}, \mathrm{THF}, 0^{\circ} \mathrm{C}$, then $\mathrm{NaBH}_{4}, \mathrm{THF}(77 \%), \mathrm{f} \mathrm{MsCl}, \mathrm{Et}_{3} \mathrm{~N}, \mathrm{CH}_{2} \mathrm{Cl}_{2},-60^{\circ} \mathrm{C}(97 \%), \mathrm{g} \mathrm{Nal}$, acetone, it (93\%), h $t$-BuOK, 18-Crown-6, THF, $-60{ }^{\circ} \mathrm{C}(47 \%), \mathbf{i} \mathrm{c}-\mathrm{HCl}, \mathrm{MeOH}$, reflux, j $\mathrm{PhSO}_{2} \mathrm{Cl}, \mathrm{Et}_{3} \mathrm{~N}, \mathrm{CH}_{2} \mathrm{Cl}_{2}, 0^{\circ} \mathrm{C}\left(60 \%, 2\right.$ steps), $\mathbf{k}-\mathrm{ClC}_{6} \mathrm{H}_{4} \mathrm{SO}_{2} \mathrm{Cl}$, $\mathrm{LiN}(\mathrm{TMS})_{2}, \mathrm{THF},-20^{\circ} \mathrm{C}-\mathrm{rt}(54 \%), \mathrm{I} \mathrm{PhSeCl}$, LiN(TMS) $)_{2}$, THF, $-20^{\circ} \mathrm{C}(14 \%), \mathrm{m} \mathrm{H}_{2} \mathrm{O}_{2}, \mathrm{THF}, 0^{\circ} \mathrm{C}(26 \%)$.

\section{Scheme 9}

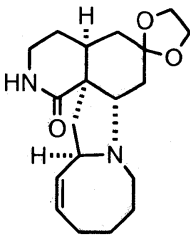

20<smiles>[R5]N1CC[C@@H]2CC(=O)C=C[C@]2(CC)C1=O</smiles><smiles>C=C1CCC1</smiles><smiles>COC(=O)C(CC1=CCCN(S)C1=O)N(C(=O)OC)C(C)(F)F</smiles>

Accordingly, we explored the synthesis of the optically active $\mathbf{2 0}$ via a more efficient method based on the Diels-Alder reaction of new dienophiles 51 with siloxydienes 52 ( path e, Scheme 9). 
We first prepared the protected serinal 55 in three steps from $N$-benzenesulfonyl-L-serine methyl ester 53 via 54.

\section{Scheme 10}<smiles>[R5]C(=O)[C@H]1COC(C)(C)N1[13CH](C)C</smiles>

53
54: $\mathrm{R}=\mathrm{OMe}$ 55: $\mathrm{R}=\mathrm{H}$<smiles>CC1(C)OC[C@H](/C=C2/CCCN([Pb])C2=O)C1=O</smiles>

59a: $\mathrm{P}^{1}=\mathrm{Bs}, \mathrm{P}^{2}=\mathrm{BOC}$ 59b: $P^{1}=P^{2}=B s$ 29: $P^{1}=M O M, P^{2}=B O C$<smiles>CN1CCC=C(C[C@@H]2COC(C)(C)N2C(=O)O[Na])C1=O</smiles>

30

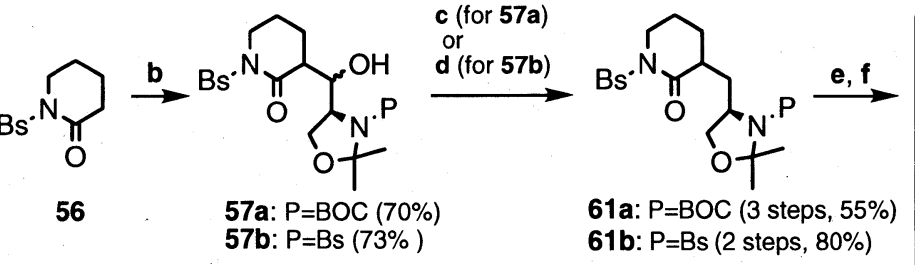

61b: $P=B s$ (2 steps, $80 \%$ )

a 1) 2,2-dimethoxypropane, $p$ - $\mathrm{TsOH}$, benzene, reflux, 2) $\mathrm{DIBAH}$, toluene, $-78^{\circ} \mathrm{C}(90 \%$ for $54,92 \%$ for 55$)$, b $\mathrm{LiN}(\mathrm{TMS})_{2}, \mathrm{THF},-60^{\circ} \mathrm{C}$, then 27 or $55,-60^{\circ} \mathrm{C}, \mathrm{c} \mathrm{1}$ ) $\mathrm{MsCl}, \mathrm{Et}_{3} \mathrm{~N}, \mathrm{CH}_{2} \mathrm{Cl}_{2}$, 2) DBU, benzene, reflux, 3) $\mathrm{H}_{2}, \mathrm{PtO}_{2}$ d 1) $\mathrm{LiN}(\mathrm{TMS})_{2}, \mathrm{THF}$; $-60^{\circ} \mathrm{C}$, then $\mathrm{PhOC}(\mathrm{S}) \mathrm{Cl}$, 2) $n-\mathrm{Bu}_{3} \mathrm{SnH}$, AlBN, benzene, reflux, e $\mathrm{PhSO}_{2} \mathrm{SPh}_{\text {, }}$ $\mathrm{LiN}(\mathrm{TMS})_{2}, \mathrm{THF},-30^{\circ} \mathrm{C}, \mathrm{f} \mathrm{mCPBA}, \mathrm{CH}_{2} \mathrm{Cl}_{2}$, then heat.

Although we anticipated extreme sensitivity of $N$-benzenesulfonyllactam to a nucleophile under basic conditions, to our delight, a key reaction of 56 with 27 using $\mathrm{LiN}(\mathrm{TMS})_{2}$ proceeded smoothly at $-60{ }^{\circ} \mathrm{C}$ to provide us $\mathbf{5 7}$ a as a mixture of diastereomers.

A similar reaction of $\mathbf{5 5}$ with $\mathbf{5 6}$ gave $\mathbf{5 7 b}$. Dehydration of 57a via mesylation followed by DBU treatment gave 59a. Originally, we had envisioned installing the $\mathrm{C} 3-\mathrm{C} 4$ double bond through the exoendo isomerization. In previous studies, we succeeded in the isomerization of the exo-enone 29 to the endo-enone 30 by use of silane-Rh-mediated conditions. In contrast to 29 , however, a similar exo-endo isomerization of either $\mathbf{5 9} \mathrm{a}$ or $\mathbf{5 9} \mathrm{b}$ to the corresponding endo-isomer failed. We, therefore, turned to the reduction-oxidation method. Catalytic hydrogenation of 59 a proceeded to give $61 \mathbf{a}$, but hydrogenation of 59b under similar conditions was unsuccessful. Therefore, we applied the deoxygenation conditions using phenoxythiocarbonate for $\mathbf{5 7 b}$ (ref. 16), and $\mathbf{6 1 b}$ was obtained in $80 \%$ yield.

The conversion of 61 to the desired enantiomerically pure dienophiles 62 was achieved by base induced thiophenylation at the 3 position of $\mathbf{6 1}$ followed by oxidative elimination using previous methods.

\section{Total Synthesis of Manzamine A and Ircinal A}

With an efficient route to the dienophile 62 established, attention was turned toward the Diels-Alder reaction of 62 with Danishefsky diene 63. Attempts to achieve Diels-Alder reaction of a new dienophile 62a with Danishefsky diene 63a were unsuccessful, leading only to extensive decomposition, probably due to the instability of the BOC group to high temperature. On the other hand, the reaction of $\mathbf{6 2 b}$ and excess amount ( 8 equiv) of $63 \mathrm{a}$ in refluxing $p$-cymene at $180^{\circ} \mathrm{C}$ for $20 \mathrm{~h}$ smoothly underwent regioselective cycloaddition. Without isolation, the cycloadduct was readily transformed into the corresponding enones slightly in favor of the desired isomer 64 after deprotection with PPTS. 


\section{Scheme 11}

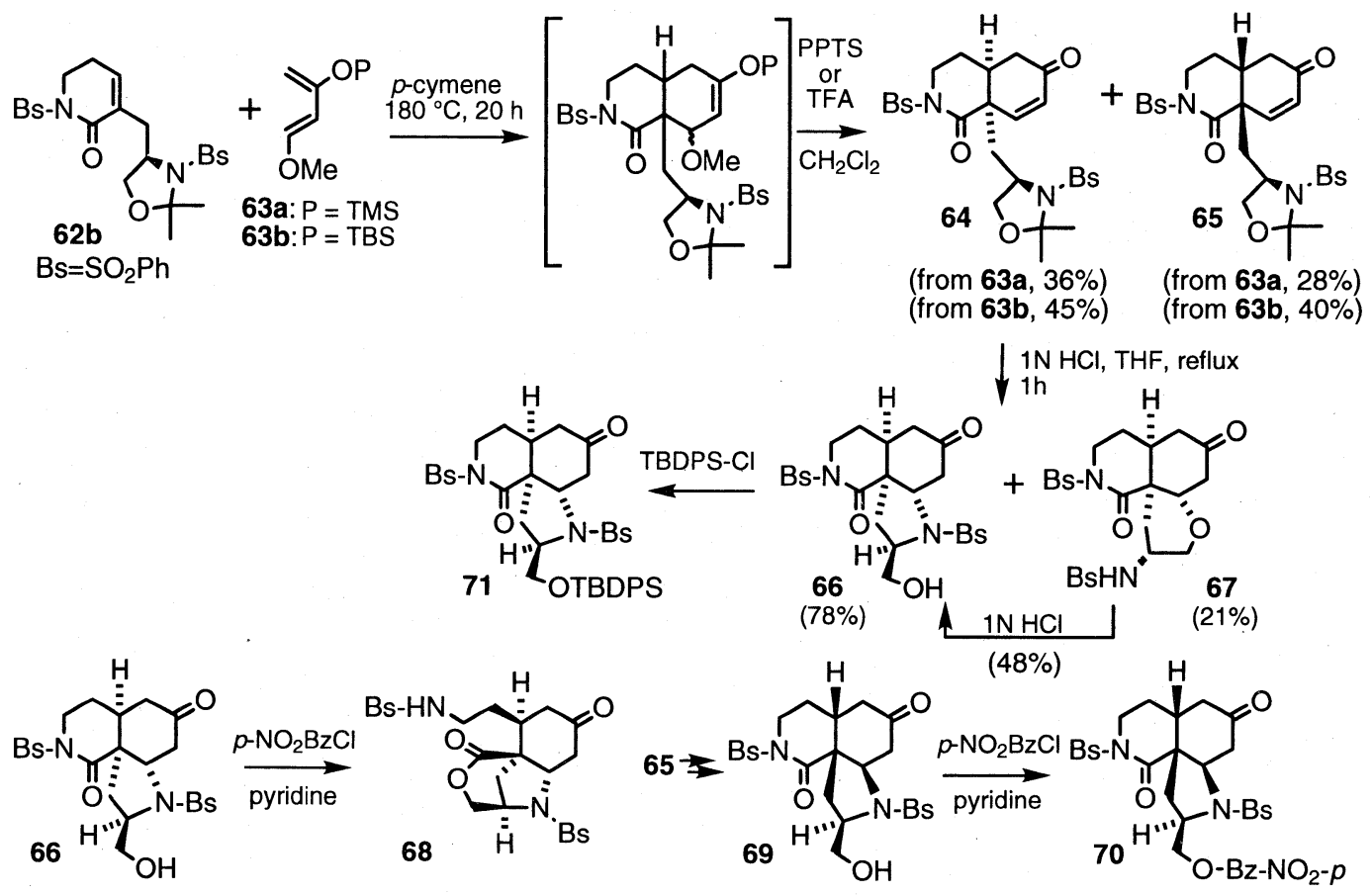

Similar reaction of $62 \mathrm{~b}$ with TBS-diene $\mathbf{6 3 b}$ afforded the corresponding enones (64 and 65 ) in $85 \%$ yield. Subsequently, the acetonide 64 was subjected to acid treatment with $1 \mathrm{~N} \mathrm{HCl}$ in THF to give a tricyclic alcohol 66, together with 67 which could readily be converted to 66 by $1 \mathrm{~N} \mathrm{HCl}$. The desired stereochemistry of 66 was secured through the chemical transformation and ${ }^{1} \mathrm{H}-\mathrm{NMR}$ spectral data.

\section{Scheme 12}

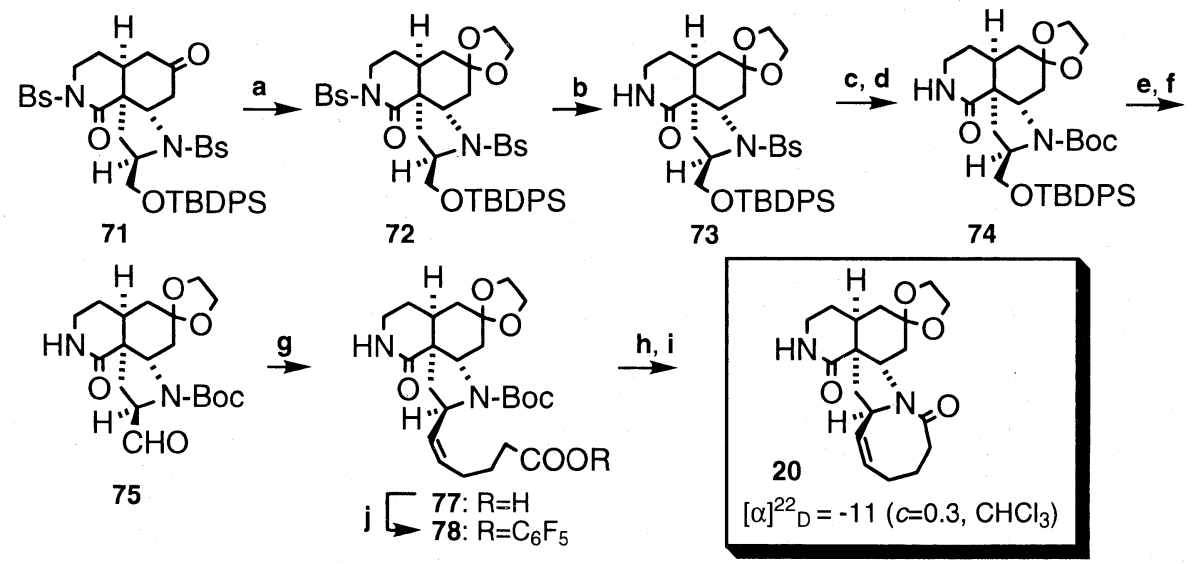

a ethylene glycol, $p-\mathrm{TsOH}$, benzene, reflux (99\%), b Na, anthracene, DME, $-65{ }^{\circ} \mathrm{C}(94 \%)$, c Na, naphthalene, DME, $-65^{\circ} \mathrm{C}$, d Boc ${ }_{2} \mathrm{O}, 1 \mathrm{~N} \mathrm{NaOH}$, rt (92\% from 73), e TBAF, THF, rt, f Dess-Martin ox. $\mathrm{CH}_{2} \mathrm{Cl}_{2}, 0^{\circ} \mathrm{C}$ (96\% from 74), $\mathbf{g ~ B r} \mathrm{Ph}_{3} \mathrm{P}^{+}\left(\mathrm{CH}_{2}\right)_{4} \mathrm{COOH}(76), \mathrm{KN}(\mathrm{TMS})_{2}$, toluene, rt (78\%), $\mathbf{h}$ TFA, $\mathrm{CH}_{2} \mathrm{Cl}_{2}$, rt, i BOP-Cl, $\mathrm{Et}_{3} \mathrm{~N}, \mathrm{CH}_{2} \mathrm{Cl}_{2}$, rt (32\% from 77), j $\mathrm{C}_{6} \mathrm{~F}_{5} \mathrm{OH}, \mathrm{DCC}$. 
When 66 was treated with $p$-nitrobenzoyl chloride in pyridine, the lactone 68 was newly formed, whereas the isomer 69, obtained from 65 in analogous manner, gave the corresponding $p$-nitrobenzoate 70, selectively. The unexpected formation of 68 supported the cis relationship of the hydroxymethyl group and the ring $A$ in 66 . The alcohol 66 was then protected with TBDPS to give 71, which was converted into the ketal 72. Deprotection of two benzenesulfonyl groups of 72, followed by reprotection with a BOC group, afforded 74.

The remaining task was elongation of the side chain to construct the azocine ring system. Deprotection of the primary TBDPS ether was followed by Dess-Martin periodinane oxidation of the derived primary alcohol to give the labile aldehyde 75. Homologation of the resulting aldehyde $\mathbf{7 5}$ using the Wittig reagent 76 furnished the olefin 77 ( $E / Z$ ratio 1:5) as the key cyclization substrate. A 1:5 ratio of the $E$ and $Z$ isomers was determined by ${ }^{1} \mathrm{H}$-NMR spectroscopy of the resultant mixture of the pentafluorophenyl ester 78. At this stage, we chose $\mathrm{BOP}-\mathrm{Cl}$ for the final cyclization (ref. 17). Thus, the $\mathrm{BOC}$ group was first deprotected and the amino acid was treated with $\mathrm{BOP}-\mathrm{Cl}$ to furnish the desired tetracyclic key compound $20\left[[\alpha]^{22} \mathrm{D}=-11\left(c=0.3, \mathrm{CHCl}_{3}\right)\right]$. Its spectroscopic properties were identical in all respects to those of $( \pm)-20$ (ref. 12,18 ).

The next step in the synthesis involved the introduction of the $\mathrm{C}_{1}$ unit to the $\mathrm{B}$ ring and functionalization of the $\mathrm{B}$ ring to construct the $\mathrm{E}$ ring system. Although this transformation appeared fairly straightforward, it proved to be rather difficult. Treatment of $\mathbf{7 1}$ with $\mathrm{MOMCl}$ provided a 1:1 mixture of O-MOM derivative 79 and $\mathrm{C}-\mathrm{MOM}$ derivative 80. Reaction of 71 with $\mathrm{ClCO}_{2} \mathrm{Me}$ gave $O$ methoxycarbonylated product $\mathbf{8 1}$ selectively. In contrast, exclusive formation of the desired ketoester 82 could be effected in $90 \%$ yield by treatment of 71 with Mander's reagent, $\mathrm{CNCO}_{2} \mathrm{Me}$ (ref. 19).

\section{Scheme 13}

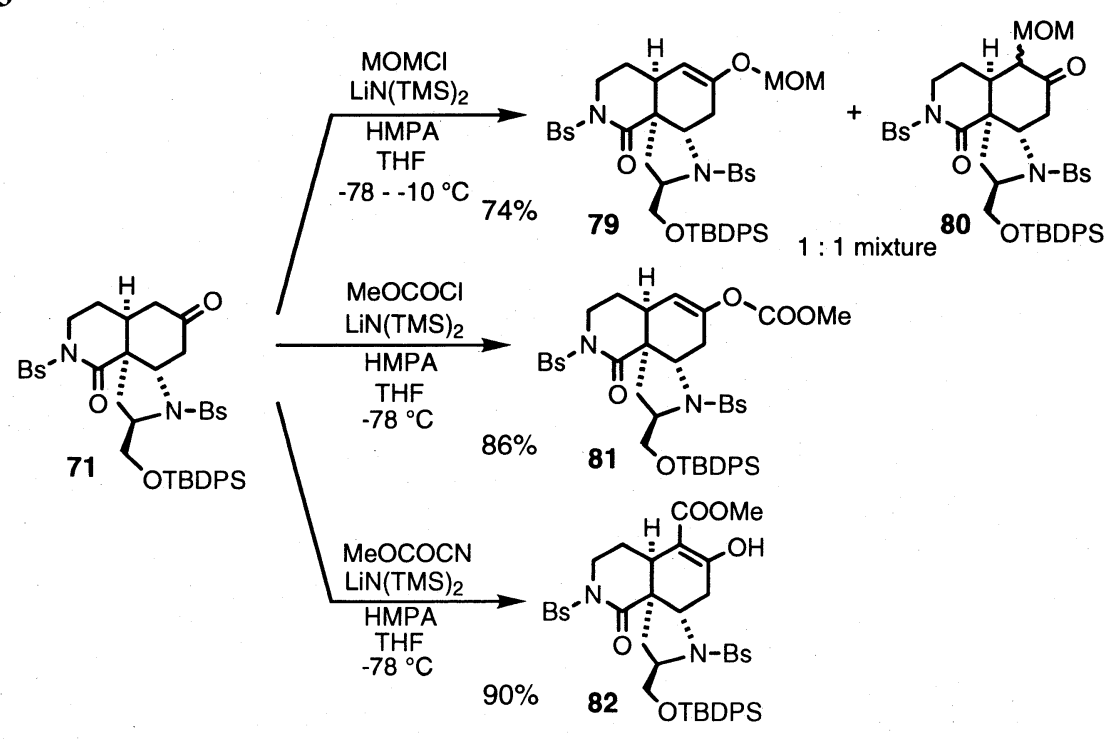

Deprotection of the benzenesulfonyl group of 82 provided lactam 83 , which was then converted to the ester 84 by reduction-dehydration. Oxidation of 84 to enone 85 was examined under a variety of reaction conditions and $\mathbf{8 5}$ was formed in the best yield of $62 \%$ by use of Salmond protocol (ref. 20). Sequential reduction of 85 with $\mathrm{NaBH}_{4} \cdot \mathrm{CeCl}_{3}$ and DIBAH followed by acylation and oxidation, provided 86 which was subjected to reaction with 8-lithio-5-octyne-1-ol MOM ether 87 and cleanly produced 88. 
Scheme 14

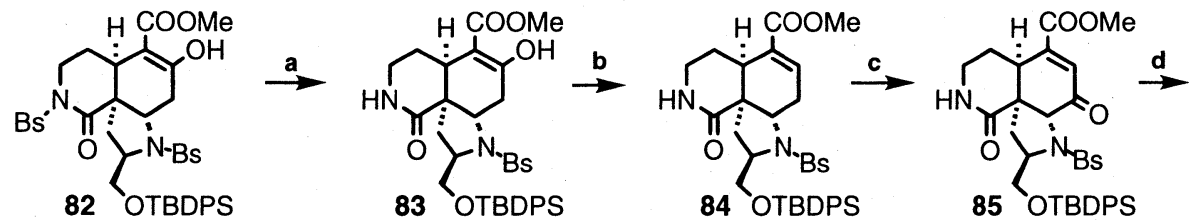

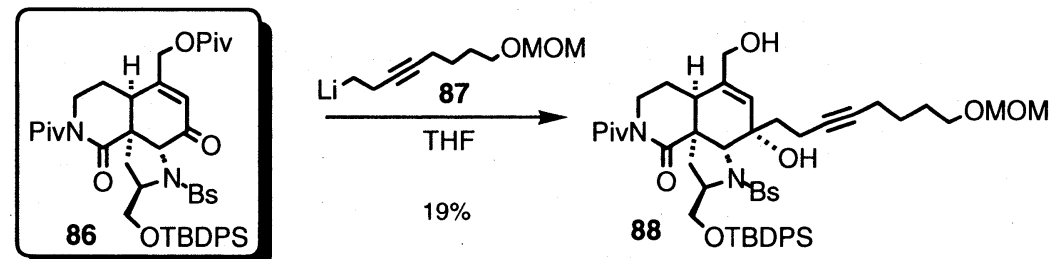

a $\mathrm{Na}$, anthracene, DME (84\%), b 1) $\mathrm{NaBH}_{4}$, 2) $\left.\mathrm{MsCl}, 3\right) \mathrm{DBU}\left(65 \%, 3\right.$ steps), $\mathrm{C} \mathrm{CrO}_{3}$ 3,5-dimethylpyrazole (62\%), d 1) $\left.\left.\mathrm{NaBH}_{4}{ }^{\circ} \mathrm{CeCl}_{3}, 2\right) \mathrm{DIBAH}, 3\right) \mathrm{PivCl}$, 4) Dess-Martin ox. ( $45 \%, 4$ steps).

\section{Scheme 15}

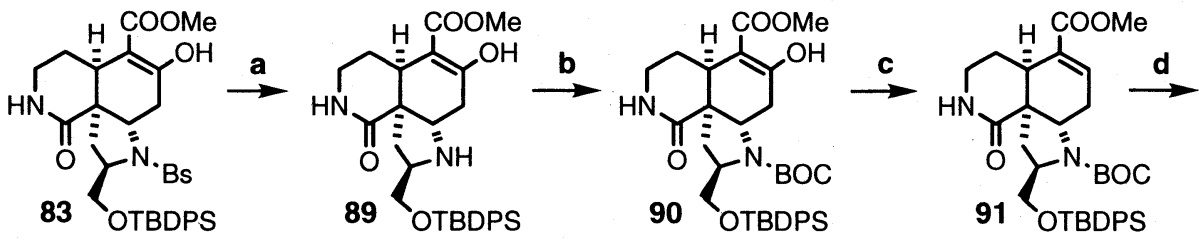

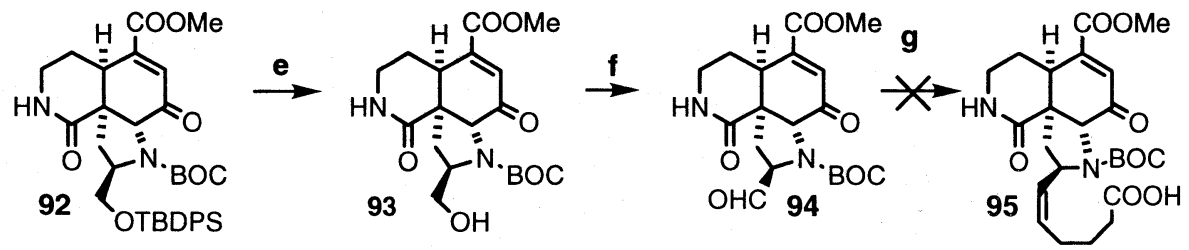

a $\mathrm{Na}$, naphtalene, DME (90\%), b Boc-ON, Et 3 N, rt (73\%), c 1) $\left.\left.\mathrm{NaBH}_{4}, 2\right) \mathrm{MsCl}, 3\right) \mathrm{DBU}(77 \%, 3$ steps) d $\mathrm{CrO}_{3}$-3,5-dimethylpyrazole (65\%), e $\mathrm{HF}$, aq. $\mathrm{CH}_{3} \mathrm{CN},-30{ }^{\circ} \mathrm{C}(92 \%)$, f Swern ox. (83\%), g 1) $\mathrm{Br}$ $\mathrm{Ph}_{3} \mathrm{P}^{+}\left(\mathrm{CH}_{2}\right)_{4} \mathrm{COOH}, \mathrm{KN}(\mathrm{TMS})_{2}$

On the other hand, replacement of the benzenesulfonyl group of 83 with a BOC group gave 90 . The submission of 90 to sequential reduction, dehydration, and oxidation gave rise efficiently to 92 . Deprotection of enone 92 by HF gave 93 . Oxidation of 93 to the aldehyde 94 was followed by Wittig reaction; however, none of the desired acid 95 was obtained.

Because high reactivity of the enone carbonyl was expected, we next converted 92 to 97. Deprotection of enone 92 by HF gave the corresponding alcohol (Scheme 16). The acylation of the resulting alcohol, followed by reduction, and protection provided 96. Deprotection of 96, followed by oxidation gave 97, which was subjected to Wittig reaction to afford the desired acid 98. Cyclization of 98 to advanced tetracyclic intermediate 99 under a variety of conditions is now under investigation . On the other hand, 97 was converted diene 100, a precursor for ring closing metathesis. Ring closing metathesis of 100 using $50 \mathrm{~mol} \%$ of $\mathbf{1 0 1}$ in diluted solution of $\mathrm{CH}_{2} \mathrm{Cl}_{2}$, gave desired tetracyclic intermediate 102 in $75 \%$ yield (Scheme 17). 
The intermediate $\mathbf{1 0 2}$ will be transformed to ircinal A (Scheme 17), which has been converted to manzamine A by Professor J. Kobayashi, of Hokkaido University (ref. 2d).

\section{Scheme 16}
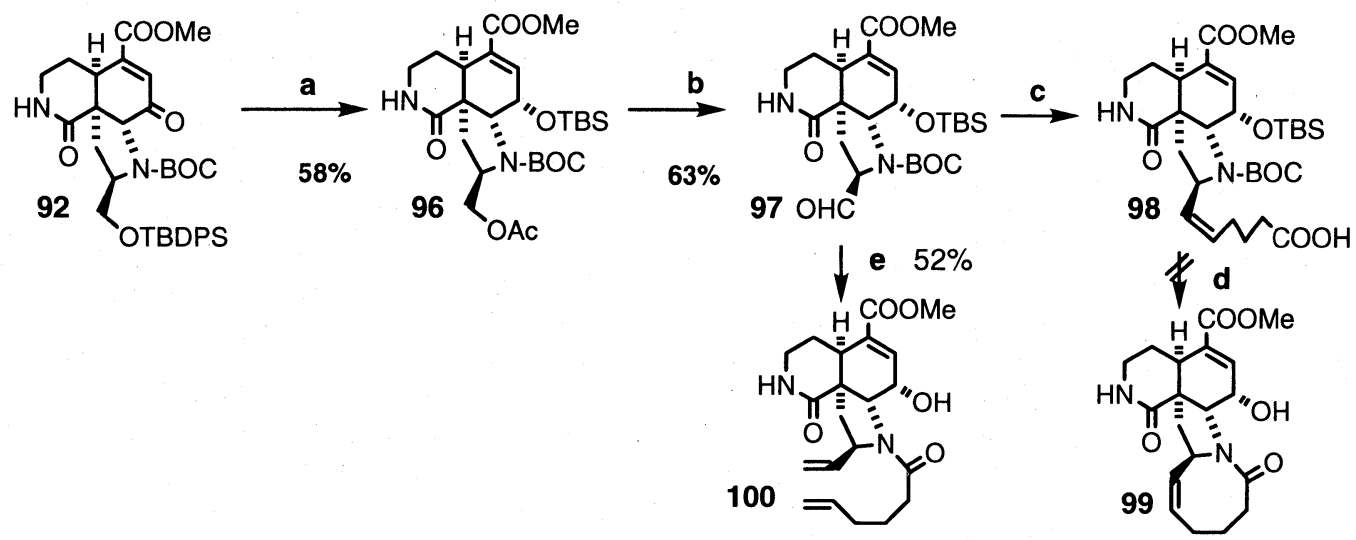

a 1) $\mathrm{HF}$, 2) $\mathrm{Ac}_{2} \mathrm{O}$, 3) $\mathrm{NaBH}_{4}, \mathrm{CeCl}_{3}$, 4) TBS-OTf, b 1) $\mathrm{NaOMe}$, 2) Swern ox. or Dess-Martin ox. c $\mathrm{Br}^{-} \mathrm{Ph}_{3} \mathrm{P}^{+}\left(\mathrm{CH}_{2}\right)_{4} \mathrm{COOH}, \mathrm{KN}(\mathrm{TMS})_{2}$, d 1) TFA, 2) FDPP, (Pr) $)_{2} \mathrm{NEt}$, e 1) $\mathrm{Br}^{-} \mathrm{Ph}_{3} \mathrm{P}^{+} \mathrm{CH}_{3}$, $\mathrm{KN}(\mathrm{TMS})_{2}$, 2) TFA, 3) $\mathrm{H}_{2} \mathrm{C}=\mathrm{CH}\left(\mathrm{CH}_{2}\right)_{3} \mathrm{COCl}, \mathrm{Et}_{3} \mathrm{~N}$

\section{Scheme 17}

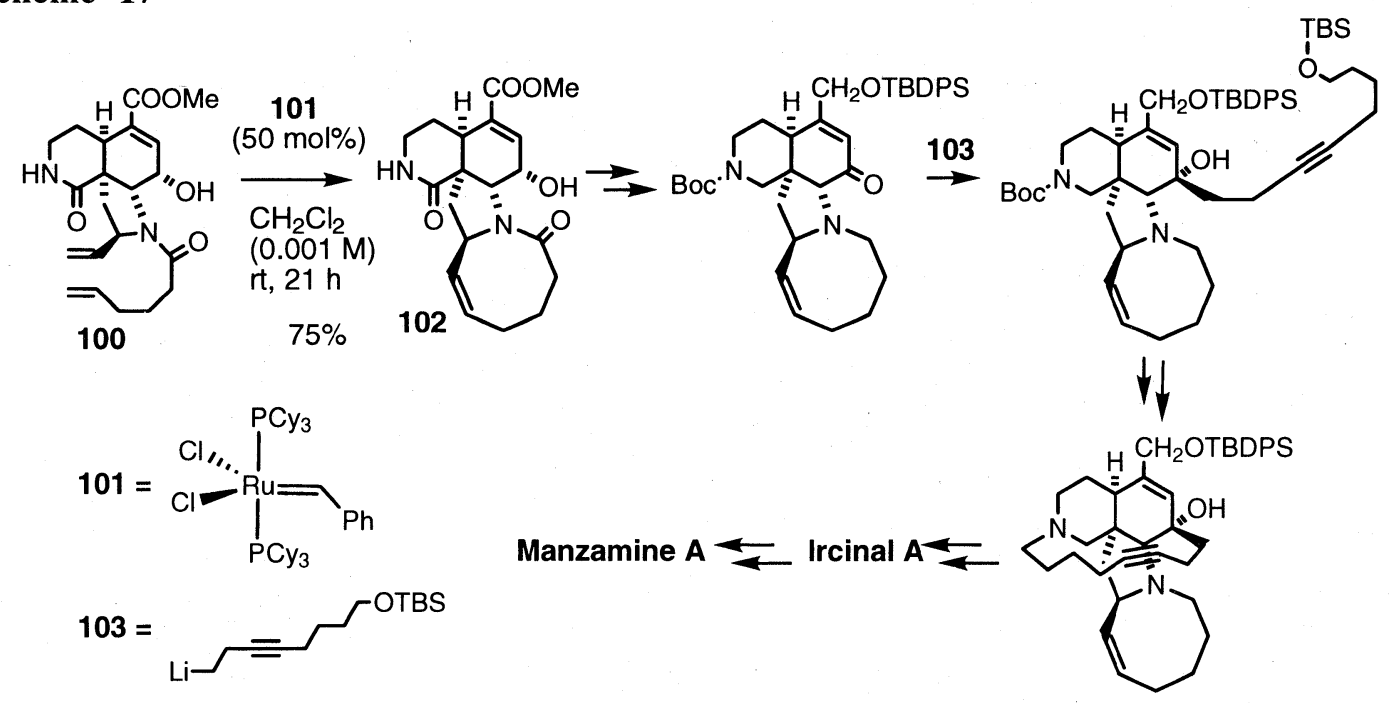

\section{Acknowledgment}

This research was supported by a Grant-in-Aid for Scientific Research from the Ministry of Science, Education, Sports and Culture. It is with great pleasure that we acknowledge the assistance of Associate Dr. M. Arisawa, Mr. Y. Kimura, Ms M. Yamabe, Ms N. Watanabe, Mr. Y. Sekine, Mr. T. Watanabe, and Ms K. Hyodo for their assistance in this synthesis. 


\section{REFERENCES}

1) R. Sakai, T. Higa, C.W. Jefford, G. Bernardinelli J. Am. Chem. Soc., 1986, 108. 6404-6405.

2) For isolation and reviews : a) H. Nakamura, S. Deng, J. Kobayashi, Y. Ohizumi, Y. Tomotaka, T. Matsuzaki, Y. Hirata Tetrahedron Lett., 1987, 28, 621-624. b) R. Sakai, T. Kohmoto, T. Higa, C.W. Jefford, G. Bernardinelli Tetrahedron Lett., 1987, 28, 5493-5496. c) D. Watanabe, M. Tsuda, J. Kobayashi J. Nat. Prod., 1998, 61, 689-692. d) K. Kondo, H. Shigemori, Y. Kikuchi, M. Ishibashi, T. Sasaki, J. Kobayashi J. Org. Chem., 1998, 57, 2480-2483.

3) For biosynthesis : a) J.E. Baldwin, R.C. Whitehead Tetrahedron Lett., 1992, 33, 2059-2062. b) J.E. Baldwin , T.D.W. Claridge, A.J. Culshaw, F.A. Heupel, V.Lee, D.R. Spring, R.C. Whitehead, R.J. Boughtfolwer, I.M. Mutton, R.J. Upton Angew. Chem., Int. Ed., 1998, 37, 2661-2663. c) A. Kaiser, X. Billot, A. Gate-Olesker, C. Marazano, B.C. Das J. Am. Chem. Soc., 1998, 120, 8026-8034.

4) a) Y. Torisawa, A. Hashimoto, M. Nakagawa, T. Hino Tetrahedron Lett., 1989, 30, 65496550. b) Y. Torisawa, A. Hashimoto, M. Nakagawa, H. Seki, R. Hara, T. Hino Tetrahedron, 1991, 47, 8067-8078. c) H. Siki, M. Nakagawa, A. Hashimoto, T. Hino Chem. Pharm. Bull., 1993, 41, 1173-1176.

5) T. Vidal, E. Magnier, Y. Langlois Tetrahedron Lett., 1998, 54, 5959-5966.

6) a) E. Magnier, Y. Langlois Tetrahedron, 1998, 54, 6201-6258, and references cited therein. b) S. Li, S. Yamamura, H. Hosomi, S. Ohba Tetrahedron Lett.., 1998, 39, 2601-2604.

7) J.D. Winkler, J.M. Axten J. Am. Chem. Soc., 1998, 120, 6425-6426.

8) S.F. Martin, J.M. Humphrey, A. Ali, M.C. Hillier J. Am. Chem. Soc., 1999, 121, 866-867.

9) J. Ma, M. Nakagawa, Y. Torisawa, T. Hino Heterocycles, 1994, 38, 1609-1618.

10) a) M. Nakagawa, Z. Lai, Y. Torisawa, T. Hino Heterocycles, 1990, 31, 999-1002, b) Y. Torisawa, M. Nakagawa, H. Arai, Z. Lai, T. Hino, T. Nakata, T. Ohishi Tetrahedron Lett., 1990, 3l, 3195-3198, c) Y. Torisawa, M. Nakagawa, T. Hosaka, K. Tanabe, Z. Lai, K. Ogata, T. Nakata, T. Ohishi, T. Hino J. Org. Chem., 1992, 57, 5741-5747.

11) M. Nakagawa, Y. Torisawa, T. Hosaka, K. Tanabe, F. Tavet, M. Aikawa, T. Hino Heterocycles, 1993, 35, 1157-1170.

12) a) M. Nakagawa, Y. Torisawa, T. Hosaka, K. Tanabe, T. Da-te, K. Okamura, T. Hino Tetrahedron Lett., 1993, 34, 4543-4546, b) Y. Torisawa, T. Hosaka, K. Tanabe, N. Suzuki, Y. Motohashi, T. Hino, M. Nakagawa Tetrahedron, 1996, 52, 10597-10608.

13) M. Tanaka, H. Mitsuhashi, M. Maruno, T. Wakamatsu Chem. Lett., 1994, 1455-1458, and references cited therein.

14) A.I. Meyers and E.W. Collington Tetrahedron, 1971, 27, 5979-5985.

15) Y. Torisawa, Than Soe, C. Katoh, Y. Motohashi, A. Nishida, T. Hino, M. Nakagawa Heterocycles, 1998, 47, 655-659 and references cited therein.

16) M.J. Robins, J.S. Wilson J. Am. Chem. Soc., 1981, 103, 932-933.

17) J. Diago-Meseguer, A. L. Palomo-Coll Synthesis, 1980, 547-551.

18) H. Uchida, A. Nishida, M. Nakagawa Tetrahedron Lett., 1999, 40, 113-116.

19) a) L.N. Mander, S.P. Sethi Tetrahedron Lett., 1983, 24, 5425-5428, b) S.R. Crabtree, W.L. Alex Chu, L.N. Mander Synlett, 1990, 169-170.

20) W.G. Salmond, M.A. Barta, J.L. Havens J. Org. Chem., 1978, 43, 2057-2059.

(Received August 3, 1999) 